\title{
A New Method to Measure the Job Satisfaction Level of an Employee
}

\section{S. M. Shahidul Islam}

Department of Mathematics, Hajee Mohammad Danesh Science and Technology University, Dinajpur, BANGLADESH

Corresponding Contact:

Email: sislam.math@gmail.com

\begin{abstract}
Job satisfaction can simply be defined as the feelings people have about their jobs. As most people spend a major part of their adult life at work, job satisfaction is an important element of individual wellbeing. Employers always try to maintain high level job satisfactions of their employees to get best services of them, because job satisfaction inspires the workforce to work honestly and efficiently. There are many factors which play vital role in the job satisfaction of an employee. We summarize them by five factors namely payment, supervision, promotion opportunities, environment of the workplace and the work itself. Using these facets, we establish a new method to measure job satisfaction level of an employee in percentage. We illustrate our method with the help of an example.
\end{abstract}

Key words

Job satisfaction, Satisfaction rank, Satisfaction ratio, Job satisfaction level

\section{INTRODUCTION}

Employees' job satisfaction is a vital matter for an institution because it directly influences the outputs of the institution. So, it is very important to measure the job satisfaction level of the employees of all organizations. We try to draw back a mathematical method to calculate job satisfaction level of the employees because there is still lack of mathematical procedure measuring job satisfaction level. A few researches already have been done on job satisfaction at the psychological point of view. Job satisfaction has been specifically defined as a pleasurable emotional state resulting from the appraisal of one's job (Stahl, 2004), an affective reaction to one's job (Locke, 1976) and an attitude toward one's job (Cranny etal, 1992). Edwin A, Locke's Range in his Affect theory job satisfaction model (1976) determined the job satisfaction by a discrepancy between what one wants in a job and what one has in a job. Model of Dispositional Theory (Judge etal, 1997) emphasizes on innate dispositions of the employees to measure the job satisfaction whereas Opponent Process Theory (Bowling etal, 2005) gives importance on emotions of employees. Beside 
these, Equity Theory (Walster etal, 1973) measures the job satisfaction on the basis of input output ratio, Discrepancy Theory (Higgins, 1999b) estimates it on the basis of anxiety \& dejection and motivation \& hygiene are the base of the Two Factor Theory (Hackman and Oldham, 1976). The Job Descriptive Index (Brayfield and Rothe, 1951) measures one's satisfaction in five facets: payment, promotions and promotion opportunities, coworkers, supervision and the work itself. We also use five factors to measure employee's satisfaction: payment, supervision, promotion opportunities, environment of the workplace and the work itself and try to define these factors as our context and usual forms. This is why; we think these five factors cover all the reasons of job satisfactions. In our paper all these five factors get equal importance because they are correlated each other for satisfaction. To establish the mathematical model we calculate the weight of each factor upon the satisfaction using the data of present payment, required payment and satisfaction ranks for each factor other than payment. Then we calculate the average of the weights and convert it into the percentage form as shown in the proposed method. In this paper, we avoid negative numbering to make this method easier for calculation and understanding.

\section{SOME Definitions}

To clear out the proposed model, the following definitions and discussions are necessary. Here we firstly defined the five factors related to job satisfactions of an employee.

Payment: Payment means monthly salary including bonuses and other financial supports to the employees. The old adage "you get what you pay for" tends to be true when it comes to staff members. Every employee does want to be paid fairly. If individuals believe they are not compensated well, they will be unhappy working for the employer. So it is an important factor for job satisfaction.

Supervision: Supervision means approach of higher authorities including the employer. To decrease dissatisfaction in this area, the employer must begin by making wise decisions when he appoints someone to the role of supervisor. Be aware that a good employee is not a good supervisor always. The role of supervisor is extremely difficult. It requires leadership skills and the ability to treat all employees fairly. The employer should teach his supervisors to use positive feedback whenever possible and should establish a set means of employee evaluation and feedback so that none feels singled out.

Promotion opportunities: In our paper, promotion means the up gradation, achievement, recognition, reward or advancement of an employee for his job with some increment of his salary. No employee is ready to do the same job for a long time; he wants his promotion after a short time. Promotion opportunities encourage the employees to do their duties with satisfaction. Employees will be motivated to perform their jobs well if they have ownership of their work. And hence it has an importance for job satisfaction of an employee.

Environment of the workplace: The working conditions, job securities, attitude of coworkers, genetic influence of the worker and interpersonal relations together means the environment of the workplace. The environment in which people work has a tremendous effect on their level of pride for themselves and for the work they are doing. Even a nice chair can make a world of difference to an individual's psyche. So a good workplace can increase the job satisfaction level.

Work itself: Every job has its own nature such as teachers teach their students in some 
institutions. Teaching is not like a managerial job. Employees should understand the work nature when they are appointed. It is important to motivate an employee in helping individuals believe that the work they are doing is significant for the society and their tasks are meaningful. Of course employees may not find their tasks interesting or rewarding, so work itself has an impact on job satisfaction of an employee.

Rank: In this paper we rank the satisfaction level of an employee for each factor by 0 to 5 . We divide the satisfaction level into six stages such as "strongly dissatisfied", "dissatisfied", "neither satisfied nor dissatisfied", "satisfied", "strongly satisfied" and "entirely satisfied" and we rank them by $0,1,2,3,4$ and 5 respectively. The rank table is as follows:

\begin{tabular}{|l|c|}
\hline Employee's satisfaction level on each factor other than payment & Satisfaction rank \\
\hline Strongly dissatisfied & 0 \\
\hline Dissatisfied & 1 \\
\hline Neither satisfied nor dissatisfied & 2 \\
\hline Satisfied & 3 \\
\hline Strongly satisfied & 4 \\
\hline Entirely satisfied & 5 \\
\hline
\end{tabular}

We use this rank table to measure the satisfaction ratio for each factor other than the payment. We can measure this satisfaction ranks for each factor asking the employee directly or indirectly. As for example, if we ask the employee "In what level (strongly dissatisfied, dissatisfied, neither satisfied nor dissatisfied, satisfied, strongly satisfied or entirely satisfied) do you like the supervision of your job? Or please rank 0 to 5 the supervision of your job."

He can answer us strongly satisfied or rank 4. Asking same type of questions we can get the satisfaction rank for other factors.

\section{Proposed Method}

Since we have summarized the reasons for job satisfaction by five factors, we have to calculate the weight (satisfaction ratio) of each factor for total job satisfaction and they are the indicators of job satisfaction. Firstly we have to collect the data of deserve payment, given payment and satisfaction rank for each factor other than payment from the employee. Secondly, we calculate satisfaction ratio $\left(\mathrm{SR}_{\mathrm{i}}\right)$ for each factor as follows:

Satisfaction ratio for payment factor,

$$
\mathrm{SR}_{1}=\frac{\text { Present monthly payment (salary) taken by employee }}{\text { Deserve monthly payment (salary) metasured by employee }}
$$

Satisfaction ratio for other than payment factor,

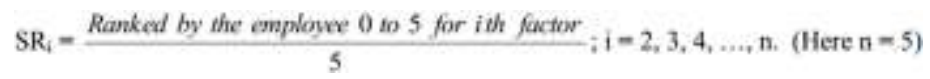

Thirdly, using the above satisfaction ratio, we calculate the job satisfaction level (JSL) as follows:

$$
\mathrm{JSI} .=\frac{S R_{1}+S R_{2}+\ldots+S R_{e}}{n} \times 100 \%
$$

The result will be given in percentage form and the resulted value is $60 \%$ or above indicates that the employee is satisfied with his/her job. 
This method will be usable if some researchers like to change the number of the factors to measure the job satisfaction level.

\section{EXAMPLE}

Mr. Ruzzak is working as an Assistant Manager of a local NGO at Dinajpur. His net monthly salary is Tk.20000 which is less by Tk.5000 of his requirement. He tells us his supervisor is so rubbish and his work itself is entirely satisfactory. He also says that the promotion opportunities and the work-environment are as usual.

To calculate his job satisfaction level, firstly we calculate satisfaction ratios as follows:

His deserve amount is Tk. 25000, as his monthly salary is Tk. 20000 which is less by Tk. 5000 of his requirement.

So, the satisfaction ratio for payment factor, $\mathrm{SR}_{1}=\frac{20000}{25000}=0.8$.

Since his supervisor is so rubbish, he is strongly dissatisfied with the supervisor and the rank is 0 for this facet. And hence the satisfaction ratio for supervisor factor is

$\mathrm{SR}_{2}=\frac{0}{5}=0$

As the work itself is entirely satisfactory for him, the rank is 5 for this factor. The satisfaction ratio for the facet work itself, $\mathrm{SR}_{3}=\frac{5}{5}=1$.

He also says the promotion opportunities and the work-environment are as usual, hence these two factors are satisfactory to him and 3 is the rank for them. So, the satisfaction ratio for the promotion opportunity, $\mathrm{SR}_{4}=\frac{3}{5}=0.6$.

And the satisfaction ratio for the environment of the workplace, $\mathrm{Sk}_{5}=\frac{3}{5}=0.6$.

Therefore, the job satisfaction level of Mr. Ruzzak is

JSL $=\frac{S R_{1}+S R_{2}+S R_{3}+S R_{4}+S R_{4}}{5} \times 100 \%=\frac{0.8+0+1+0.6+0.6}{5} \times 100 \%$

$=60 \%$

Since the job satisfaction level of Mr. Ruzzak is $60 \%$, he is satisfied with his job.

\section{Discussion}

If JSL lies on or above $60 \%$ (or each satisfaction ratio lies among 0.6 to 1.0 ), then the probability of employee's job changing will be very low and the services given by the employee will be high. And if JSL be in between $50 \%$ to $59 \%$, then the employee is neither satisfied nor dissatisfied with the job and hence his services will not be on required level. Otherwise, the employee is not satisfied with his job and hence he always will try to switch off his job and the employer will get services by him with unsatisfied level. To get better services by the employees, the employer should maintain the JSL on or above $60 \%$ of each employee under him. Sometimes, offer of big amount of payment from other institution influence to switch off the job but it has no significance for job satisfaction. 


\section{REFERENCES}

Bowling, N.A., Beehr, T.A., Wagner, S.H., \& Libkuman, T.M. (2005). Adaptation-Level Theory, Opponent Process Theory, and Dispositions: An Integrated Approach to the Stability of Job Satisfaction. Journal of Applied Psychology, 90(6), 1044-1053

Brayfield, Arthur H., Rothe, Harold F.: An index of job satisfaction, Journal of Applied Psychology, Vol 35(5), Oct 1951, 307-311

Cranny, Smith \& Stone, 1992 cited in Weiss, H. M. (2002). Deconstructing job satisfaction: separating evaluations, beliefs and affective experiences. Human Resource Management Review, 12, 173194, p. 174

Higgins, E.T. (1999b). When do self-discrepancies have specific relations to emotions? The secondgeneration question of Tangney, Niedenthal, Covert, and Barlow (1998). Journal of Personality and Social Psychology, 77, 1313-1317

J.R. Hackman, G. R. Oldham (1976). "Motivation through design of work". Organizational behaviour and human performance 16(2): 250-279

Judge, T.A, Locke, E. A, \& Durham, C.C. (1997). The dispositional causes of job satisfaction: A core evaluations approach in organizational behavior, 19, 151-188.

Locke, 1976 cited in Brief, A. P., \& Weiss, H. M. (2001). Organizational behavior: affect in the workplace. Annual Review of Psychology, 53, 279-307, p. 282

Stahl, Michael J. Encyclopedia of Health Care Management. Sage Publications, Inc., 2004, p. 311

Walster, E.E. Berscheid and G.W. Walster. (1973). “New Directions in Equity Research.” Journal of Personality and Social Psychology. Pp. 151-176. 
Online ISSN: 2409-3629

Online Archive Link: https://abc.us.org/ojs/index.php/ei/issue/archive 